\title{
Developing the Pecan Scab Fungus on Susceptible and Resistant Host and Nonhost Leaves
}

\author{
I.E. Yates and Donnie Maxey \\ R.B. Russell Agricultural Research Center, Agricultural Research Service, U.S. Department of Agriculture, \\ Athens, GA 30613
}

Seonju Lee

Department of Plant Pathology, University of Georgia, Athens, GA 30602

Darrell Sparks

Department of Horticulture, University of Georgia, Athens, GA 30602

C.C. Reilly

Southeastern Fruit and Tree Nut Laboratory, Agricultural Research Service, U.S. Department of Agriculture, Byron, Ga 31008

Additional index words. Carya illinoensis, Cladosporium caryigenum, germination, appressoria, subcuticular hyphae, hostpathogen interface, scab resistance, pecan breeding

\begin{abstract}
Germ tube, appressorium, and subcuticular hypha development were analyzed on host and nonhost leaves for Cladosporium caryigenum (Ell. et Lang. Gottwald), the fungus causing scab on pecan [Carya illinoinensis (Wangenh.) C. Koch]. Plant features characterized for supporting fungal growth were genotype, adaxial and abaxial leaf surfaces, and leaf maturity. Germ tubes and appressoria developed on all plant leaves, despite genotype, leaf surface, or maturity. Germ tube frequency on the susceptible host, 'Wichita', was lower than on the resistant host, 'Elliott', but was not significantly different from the nonhost, tobacco (Nicotiana tabacum L.). Appressoria formed with equal frequency on leaves of both pecan cultivars and tobacco. Adaxial and abaxial leaf surfaces were not different within any given genotype for supporting fungal development. Immature leaves of 'Elliott', but not of 'Wichita', had a higher frequency of germ tubes and appressoria than mature leaves. Subcuticular hyphal development occurred only on immature leaves of susceptible 'Wichita' pecan. Hence, subcuticular hyphal development is a prime candidate for being the fungal stage specific for host susceptibility. Resistance to $C$. caryigenum infection appears to be expressed at the plant site beneath the cuticle as fungal hyphae did not develop in a resistant pecan genotype or on nonhost leaves. Thus, resistance to the fungus causing pecan scab likely is expressed after both germ tube and appressorium development and operates beneath, not on the surface, of the leaf cuticle. Furthermore, technology developed to make these assessments would be adaptable in pecan breeding programs to screen for scab resistance.
\end{abstract}

Cultivars of pecan, a native North American hickory (Carya), were developed to produce an economically important fruit crop. Nut yields in the world's major pecan producing region, the southeastern U.S., are often limited by scab disease caused by the fungus Cladosporium caryigenum. Developing leaves, fruit, and shoots are susceptible to infection and subsequent damage, and even death.

Genetic resistance to scab exists within the pecan germplasm. Additionally, leaves and shoots of susceptible cultivars acquire resistance with maturity (Demaree, 1924; Gottwald, 1985). Several investigations have compared chemical and morphological features of resistant and susceptible pecan leaves and shoots to determine features accounting for resistance to $C$. caryigenum. Secondary metabolites present within the leaf and on the leaf surface have been characterized (Chortyk et al., 1995; Gueldner et al., 1994; Hedin et al., 1979; Wood et al., 1988), and morphological features of shoots and leaves (Cason and Yates, 1991; Wetzstein and Sparks, 1983; respectively). However, neither chemical nor structural characters have been identified that conclusively account for either genetic or maturity acquired resistance to infection.

Received for publication 20 June 1995. Accepted for publication 25 Oct. 1995. The most able technical assistance of Joyce Lambert is gratefully acknowledged. The cost of publishing this paper was defrayed in part by the payment of page charges. Under postal regulations, this paper therefore must be hereby marked advertisement solely to indicate this fact.
One reason definitive factors have not been identified with disease resistance in pecan is because the mode of resistance is unknown. Neither the exact plant cell nor the fungal stage of development at which the disease process is arrested has been reported for host or nonhost genotypes. Identifying both the cellular type and fungal growth stage interrupted during a resistance response to $C$. caryigenum is important for targeting pecan scab control measures and developing breeding strategies.

Another problem with understanding the pecan-C. caryigenum interrelationship is the variable scab susceptibility of pecan cultivars growing in different geographic locations (Sparks, 1992). For example, ten cultivars were assessed for scab susceptibility in Louisiana and Florida and the reported values converted to a scale of 0 (no scab) to 10 (severe scab). Only four cultivars, 'Elliott', 'Mahan-Stuart', 'Moreland', and 'Success', were within one unit of susceptibility. 'Caddo', 'Choctaw', 'Desirable', and 'Farley' were more susceptible in Louisiana. On the other hand, 'Curtis' and 'Stuart' were more susceptible in Florida. Variable cultivar responses in separate geographic regions are presumably due to different races of $C$. caryigenum. However, methodology does not exist for validation of this assumption.

Host plant resistance has been studied extensively in many hostpathogen interactions (Callow et al., 1987), but not pecan and $C$. caryigenum. The objective of the current research was to determine the developmental stage at which C. caryigenum growth is halted and the leaf tissue associated with cessation of fungal growth in host and 
nonhost interactions. Germ tube, appressorium, and subcuticular hyphae development of $C$. caryigenum conidia were analyzed with light and electron microscopy following inoculation under controlled environmental conditions of host (pecan) and nonhost [tobacco (Nicotiana tabacum L.), tomato (Lycopersicon esculentum Mill.), and corn (Zea mays L.)] leaves.

\section{Materials and Methods}

Plant material. Immature, expanding leaves of the $C$. caryigenum host plant, pecan, and the nonhost plants, tobacco, tomato, and corn were collected from greenhouse grown plants. Mature, fully expanded pecan leaves about 2 months post budbreak also were analyzed from field grown trees maintained by standard practices, except omitting fungicide applications. Both immature and mature leaves were examined for a highly resistant ('Elliott' ) and a highly susceptible ('Wichita') pecan cultivar. Leaves of susceptible cultivars are subject to infection when less than about 28 days old (Demaree, 1924; Gottwald, 1985). Immature pecan leaves used in this study were 7 to 12 days old. A continuous supply of immature leaves was maintained by pruning plants at monthly intervals during active growth. Leaves of nonhost plants were 10 days old from 'Hicks' tobacco, 'Sweet Million' tomato, and 'Silver Queen' corn.

Cladosporium caryigenum source and inoculation. 'Wichita' trees with young developing leaves maintained in the greenhouse with monthly pruning were placed in an orchard under 'Cherokee'

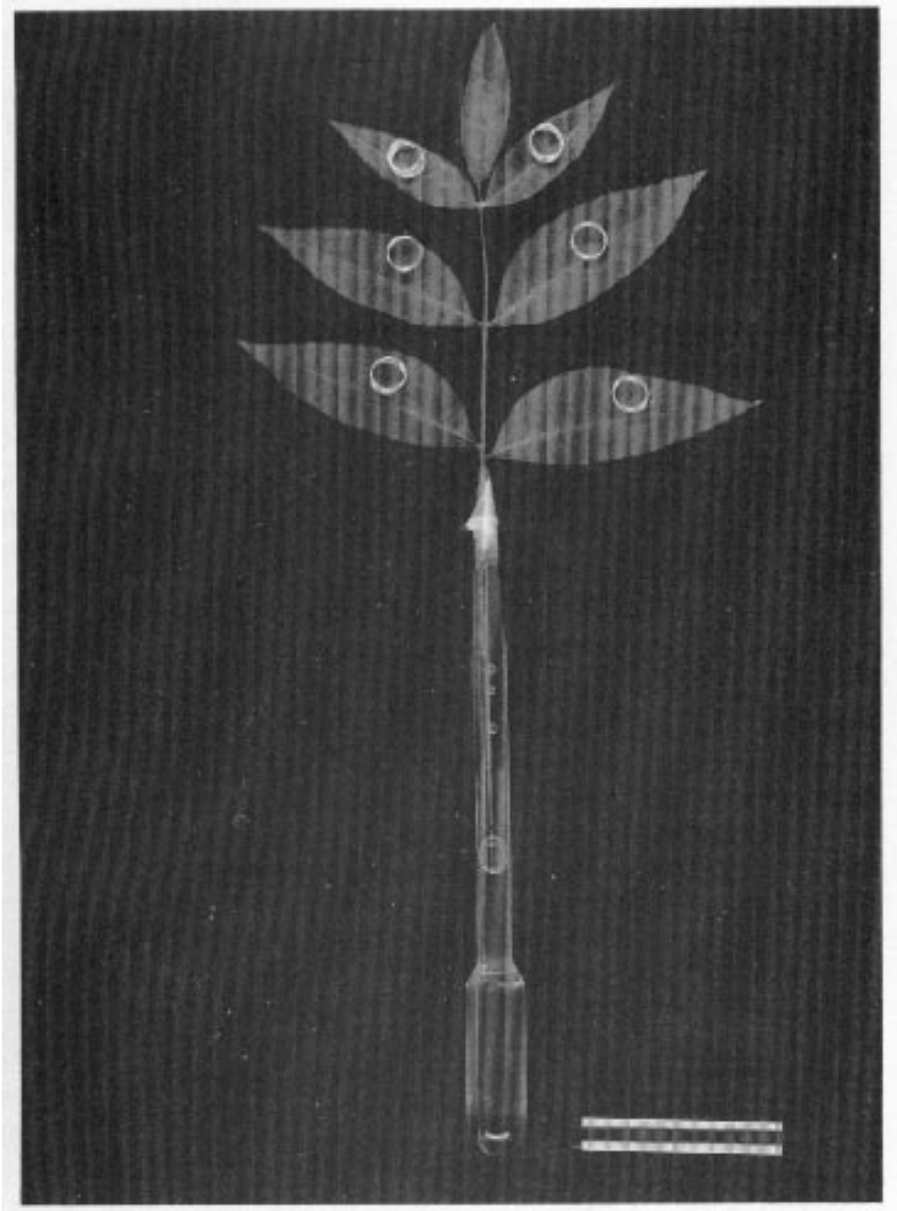

Fig. 1. Pecan leaf prepared for inoculation with petiole inserted in a vial filled with water. Vial orifice sealed with parafilm. Wells created for conidia inoculum with plastic rings attached to leaf surface with lanolin paste. Leaves from other plants were treated similarly. Bar $=4 \mathrm{~cm}$. pecan trees with scab infection. Overhead sprinklers were used to create the humid environment required for disease development. Sprinklers operated on a $48 \mathrm{~h}$ cycle with $12 \mathrm{~h}$ on from noon until midnight and $36 \mathrm{~h}$ off. After 8 days, the 'Wichita' trees were transferred to the greenhouse. Active lesions developing on 'Wichita' leaves were scraped gently with a spatula to obtain conidia. A suspension containing 60 conidia/ $\mu$ l sterile deionizeddistilled $\mathrm{H}_{2} \mathrm{O}$ was used for inoculation onto leaves of host and nonhost plants.

Excised leaves from all plants were prepared for inoculation by inserting the petiole in a vial filled with water, as illustrated for pecan (Fig. 1). The vial orifice was sealed with parafilm. Plastic rings were coated with lanolin and attached to leaves or leaflets to create a well to hold $50 \mu \mathrm{l}$ of $C$. caryigenum conidial inoculum. Inoculated leaves were incubated $48 \mathrm{~h}$ in a dew chamber (Sure-Temp, Apex, N.C.) set at $25 \mathrm{C}$ and $100 \% \mathrm{RH}$ with incandescent light providing a $14 \mathrm{~h}$ photoperiod of $40 \mu \mathrm{mol} \cdot \mathrm{m}^{-2} \cdot \mathrm{s}^{-1}$. Samples were removed from the dew chamber, sealed in plastic bags, and maintained at $21 \mathrm{C}$ for 5 days with a $14 \mathrm{~h}$ photoperiod provided by cool white fluorescent $40 \mathrm{~W}$ bulbs (General Electric, Nela Park, Cleveland, Ohio). Treatment conditions were adequate for germination, appressorium formation, and subcuticular hyphae development as reported in the classic study by Latham and Rushing (1988).

Microscopy. Leaf tissues were examined by light microscopy to quantify the frequency of germ tubes, appressoria, and subcuticular hyphae. Samples were immersed in clearing solution $(250 \mathrm{mg}$ chloral hydrate/100 $\mathrm{ml}$ water) for 2 to 3 days for pecan and 12 to $24 \mathrm{~h}$ for tomato, tobacco, and corn. Care was necessary with tobacco to prevent agitation as conidia were easily displaced. Cleared leaf tissues were stained for 18 to $24 \mathrm{~h}$ with $2 \%$ acid fuchsin in $70 \%$ ethanol diluted with a mixture of saturated chloral hydrate and 95\% ethanol (Latham and Rushing, 1988). Stained leaf tissues were destained for 1 to 2 days and then mounted in lactophenol (McBryde, 1936). Specimens were examined with a microscope (Leitz Dialux 22 EB; Leica, Wetzlar, Germany) equipped with an ocular micrometer.

Cladosporium caryigenum development was analyzed 7 days after inoculation on 10 different leaf samples for each genotype or leaf feature studied. Exceptions to this were that only nine and seven leaf samples were examined for the abaxial epidermis of 'Wichita' pecan and tobacco, respectively. Conidia with and without germ tubes, germ tubes with and without appressoria, and appressoria with and without subcuticular hyphae were counted for at least ten host-pathogen interaction sites on each leaf sample and calculated as percentages. An early infection index was determined by totaling the percentage of these three events on each leaf piece. The highest sum for a leaf was set at 100 and values for all other leaves expressed relative to the highest sum. Length of a minimum of seven germ tubes was measured on the abaxial surface of immature leaves for at least five leaf samples for each genotype. The minimum number of germ tubes measured was 51 for tobacco and the maximum, 310 for 'Wichita' pecan. Data were treated by analysis of variance and means separated by least significant difference (Gomez and Gomez, 1984).

Higher plant features evaluated with regard to $C$. caryigenum development were genotype, adaxial and abaxial leaf surface, and host leaf maturity. Values for immature leaves were used to analyze genotype and leaf surface, but values for both immature and mature leaves were used to analyze host leaf maturity.

Abaxial leaf surface morphology of each genotype was examined by scanning electron microscopy (SEM) for sections removed midway of the total leaf length. Samples were fixed overnight at 4C in $2 \%$ glutaraldehyde in $0.085 \mathrm{M}$ cacodylate buffer $(\mathrm{pH} 7.2)$, 
dehydrated in an ethanol series, critical-point dried, mounted on aluminum stubs, and coated with gold-palladium. Conidia development on leaves and leaf surface morphology were examined at 12 and $5 \mathrm{kV}$, respectively, with a SEM (Philips 505; North American Philips Corp., Mahwah, N.J.)

\section{Results}

Quantifying C. caryigenum interactions with host and nonhost leaves. Higher plant features analyzed with respect to $C$. caryigenum growth were genotype, leaf surface by genotype, and pecan leaf maturity (Figs. 2, 3, and 4, respectively). The influence of these plant features on the overall infection process was expressed by the early infection index (Figs. 2A, 3A, and 4A), a relative value obtained after combining measurements of $C$. caryigenum specific growth stages. Specific fungal developmental stages quantified as percentages were conidia forming germ tubes (Figs. 2B, 3B, and 4B), germ tubes forming appressoria (Figs. 2C, 3C, and 4C), and appressoria forming subcuticular hyphae (Figs. 2D, 3D, and 4D).

Genotypes were characterized for fungal activity on the adaxial and abaxial surfaces of immature leaves. Fungal development was different among all genotypes as the early infection index decreased stepwise from 'Wichita', 'Elliott', tobacco, tomato, and corn (Fig: 2A). Individual infection events of percent germ tube,
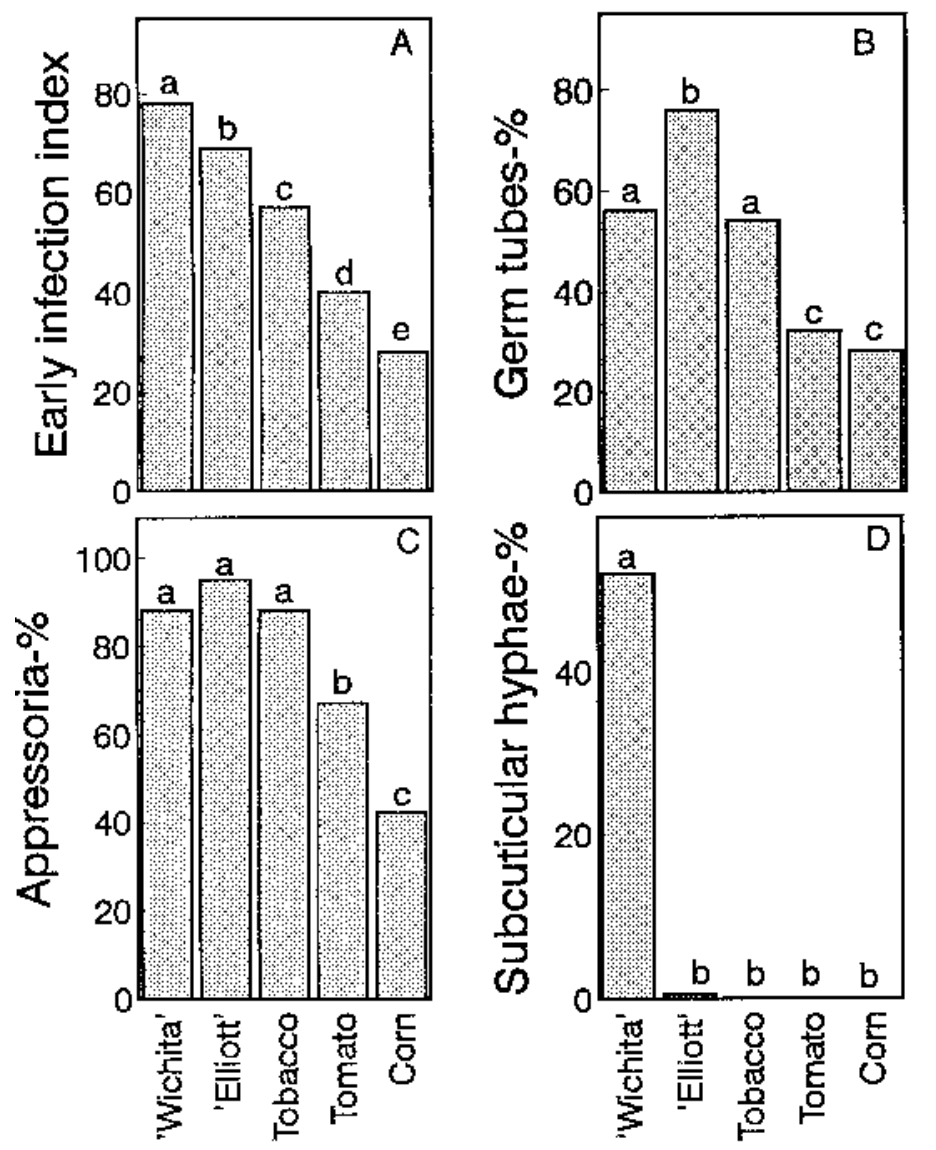

Genotype

Fig. 2. Genotype influence on early infection index (A) and on specific stages of Cladosporium caryigenum development including formation of germ tubes (B), appressoria (C), and subcuticular hyphae (D). Early infection index is a relative value determined by totaling the percentages of conidia with germ tubes, germ tubes with appressoria, and appressoria with subcuticular hypha. Values are expressed relative to the highest sum set at 100. Means with a common letter are not different $(P \leq 0.05)$ by least significant difference test.
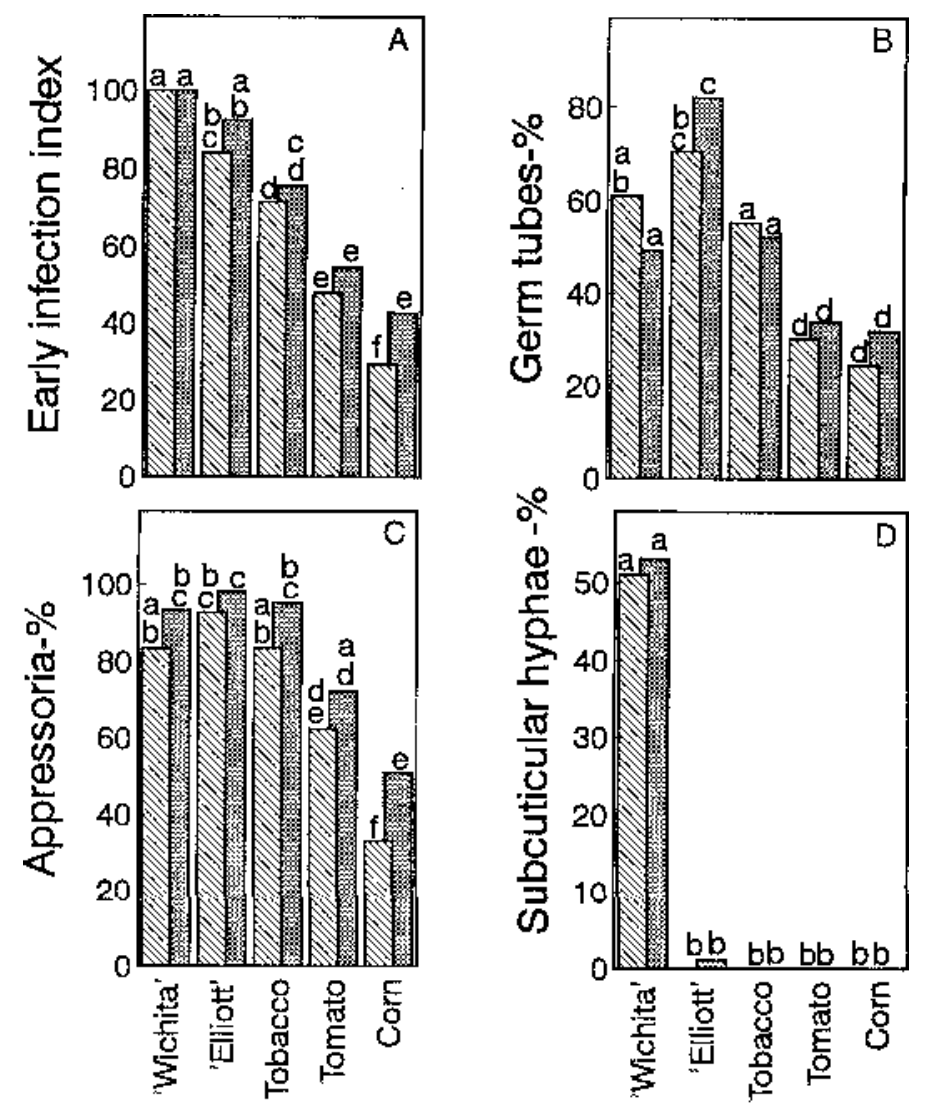

\section{Leaf surface Adaxial : Abaxial}

Fig. 3. Adaxial and abaxial leaf surface influence on early infection index (A) and on specific stages of Cladosporium caryigenum development including formation of germ tubes (B), appressoria (C), and subcuticular hyphae (D). Early infection index is a relative value determined by totaling the percentages of conidia with germ tubes, germ tubes with appressoria, and appressoria with subcuticular hypha. Values are expressed relative to the highest sum set at 100. Means with a common letter are not different $(P \leq 0.05)$ by least significant difference test.

appressorium, and subcuticular hypha formation did not follow the same stepwise pattern (Fig. 2 B-D). Germ tube frequency for the resistant host leaves of 'Elliott' pecan was significantly higher than all other genotypes (Fig. 2B). The susceptible host, 'Wichita' pecan, and tobacco were the plants with the next highest germ tube frequency. Tomato and corn produced $50 \%$ fewer germ tubes than other genotypes. Appressoria formed on all genotypes, but with significantly less frequency on tomato and corn (Fig. 2C). Subcuticular hyphal development was the specific fungal infection stage that separated susceptible host leaves of 'Wichita' pecan from resistant host leaves of 'Elliott' pecan and nonhost leaves (Fig. 2D). Subcuticular hyphae were formed by $50 \%$ of the appressoria on 'Wichita leaves. In contrast, subcuticular hyphae 'developed from $<2 \%$ of the appressoria on 'Elliott' leaves and not at all from appressoria on nonhost leaves.

Adaxial and abaxial leaf surfaces within a genotype were not isignificantly different for supporting $C$. caryigenum conidial development, except for corn (Fig. 3 A-D). A significant difference for corn adaxial and abaxial leaf surfaces in the early infection index (Fig. 3A) was not a reflection of higher frequency of germ 'tubes (Fig. 3B), but of appressoria (Fig. 3C). Subcuticular hyphae were observed with equal frequency on the abaxial and adaxial leaf surface of 'Wichita' pecan leaves, minimum on 'Elliott', and were minimal or nonexistent on other genotypes, regardless of leaf surface (Fig. 3D).

Leaf maturity influenced the early infection index for both pecan cultivars, regardless of susceptibility to scab disease (Fig. 4A). The early infection index for the susceptible 'Wichita' and the 



Leaf maturity 8 immature 풉 Mature

Fig. 4. Immature and mature leaf surfaces influence on early infection index $(\mathbf{A})$ and on specific stages of Cladosporium caryigenum development including formation of germ tubes (B), appressoria (C), and subcuticular hyphae (D). Early infection index is a relative value determined by totaling the percentages of conidia with germ tubes, germ tubes with appressoria, and appressoria with subcuticular hypha. Values are expressed relative to the highest sum set at 100. Means with a common letter are not different $(P \leq 0.05)$ by least significant difference test.

resistant 'Elliott' (Fig. 4A) was higher for immature, than mature, leaves. Immature leaves of 'Wichita' were significantly higher than those of 'Elliott', but no difference existed between cultivars for mature leaves.

Germ tube and appressorium frequency did not differ with leaf maturity for 'Wichita', but both fungal stages were more frequent on immature than mature leaves of 'Elliott' (Fig. 4 B and C). Germ tube development was significantly more frequent on immature 'Elliott' than 'Wichita', but less frequent on mature 'Elliott' than 'Wichita' (Fig. 4B). The frequency of appressoria did not differ between the two cultivars for corresponding leaf maturity stages. Again, subcuticular hyphal development was remarkably more frequent in susceptible immature leaves of 'Wichita' than mature leaves of either cultivar, as well as immature 'Elliott' leaves. An occasional subcuticular hypha was observed in both mature 'Wichita' leaves and immature 'Elliott' leaves. However, these hyphae occurred at a low frequency of $2 \%$.

Morphological examination of host and nonhost interactions. Germ tube length and appressorium structure were variable regardless of genotype, leaf surface or pecan leaf maturity. Germ tubes could be short $(<5 \mu \mathrm{m})$ or long $(>20 \mu \mathrm{m})$ and with or without appressoria, even on nonhost plants such as corn (Fig. 5 A and B). Likewise, short and long germ tubes with single or double lobed appressoria were observed on host plants whether resistant (Fig. 6 A and B) or susceptible (Fig. 7 A and B). In addition, germ tube and appressorium morphology were variable on immature (Fig. 7) and mature (Fig. 8) leaves, as well as on both leaf surfaces. Germ tubes
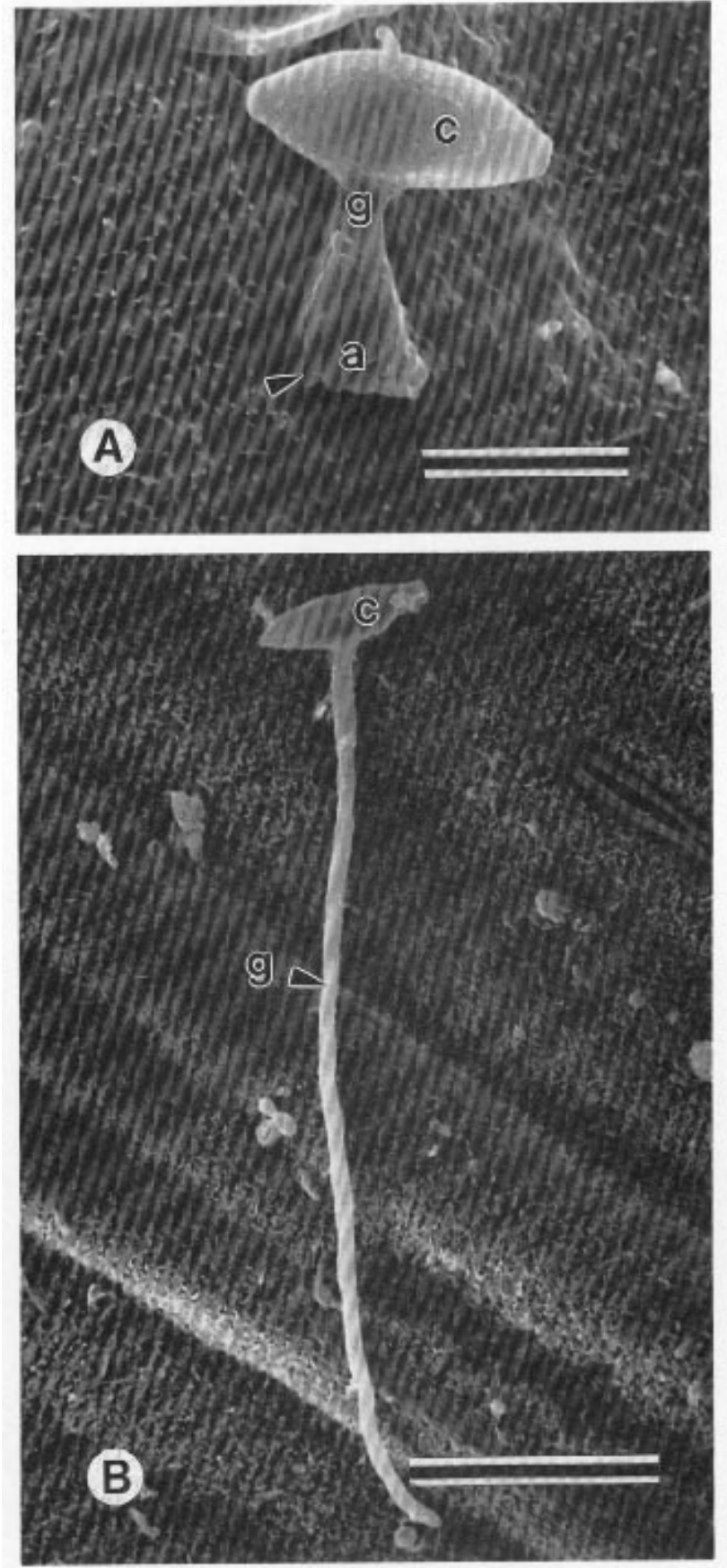

Fig. 5. Variable development of germ tubes and appressorium on the nonhost plant, corn. Conidium with barely apparent germ tube and double lobed appressorium with point indicating apparent secretion around appressorium periphery (A). Conidium with very long germ tube and no appressorium (B). Abbreviations: $\mathrm{c}=$ conidium, $\mathrm{g}=$ germ tube, $\mathrm{a}=$ appressorium. Bars $=10 \mu \mathrm{m}(\mathbf{A}), 20 \mu \mathrm{m}(\mathbf{B})$.

with attached appressorium frequently developed in a direction opposite of an open stomate (Figs. 7B and 8A). Appressoria appeared to form leaf penetration sites directly through the cuticle.

In spite of variable germ tube length within all genotypes, measurements of germ tube length revealed consistent differences among genotypes (Fig.9). Germ tubes were significantly shorter on host than on nonhost leaves and on the resistant 'Elliott' pecan than on the susceptible 'Wichita' pecan. Germ tube lengths on tomato were about double those on the other nonhost plants, tobacco and corn.

Adhesive interactions were evident between nonhost (Fig. 5A) and host (Fig. 6B) leaves with C. caryigenum. The adhesion of the 

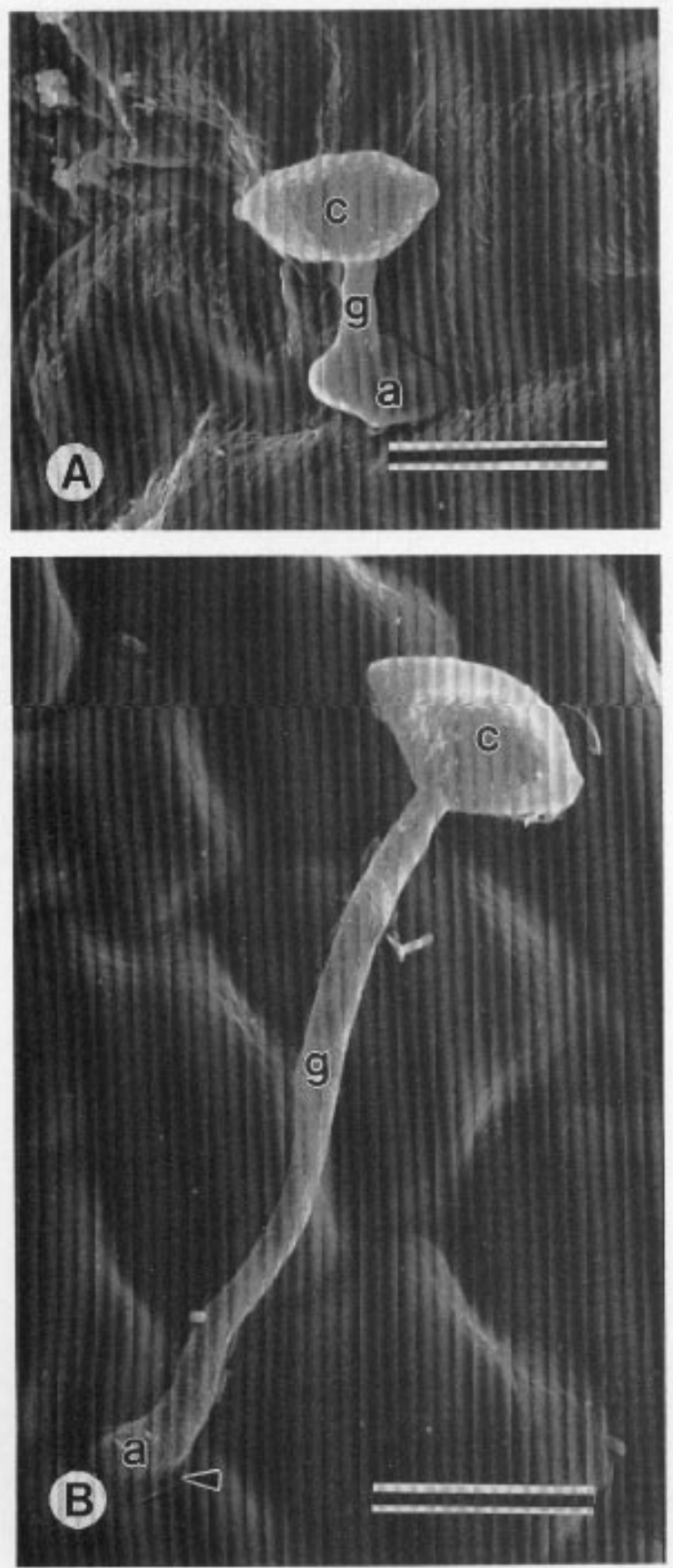

Fig. 6. Variable development of germ tubes and appressoria on immature leaves of the resistant host plant, 'Elliott' pecan. Conidium with short germ tube and double lobed appressorium (A). Conidium with long germ tube and single lobed appressorium with point indicating apparent secretion around appressorium periphery $(\mathbf{B})$. Abbreviations: $\mathrm{c}=$ conidium, $\mathrm{g}=$ germ tube, $\mathrm{a}=$ appressorium. Bars $=10 \mu \mathrm{m}(\mathbf{A}$ and $\mathbf{B})$.

fungus to the plant appeared to involve secretions deposited at the encounter sites. Appressoria were the most common site where secretions were observed, but germ tubes and conidia often were surrounded by secretory material.

Abaxial surface morphology of host and nonhost leaves was examined to determine whether leaf surface characteristics were responsible for frequency of fungal development. The most striking features were characteristics and density of trichomes (Figs. 10 and 11). Peltate trichomes were observed on immature and mature leaves of susceptible 'Wichita' (Fig. 10 A and B) and resistant 'Elliott' (Fig.
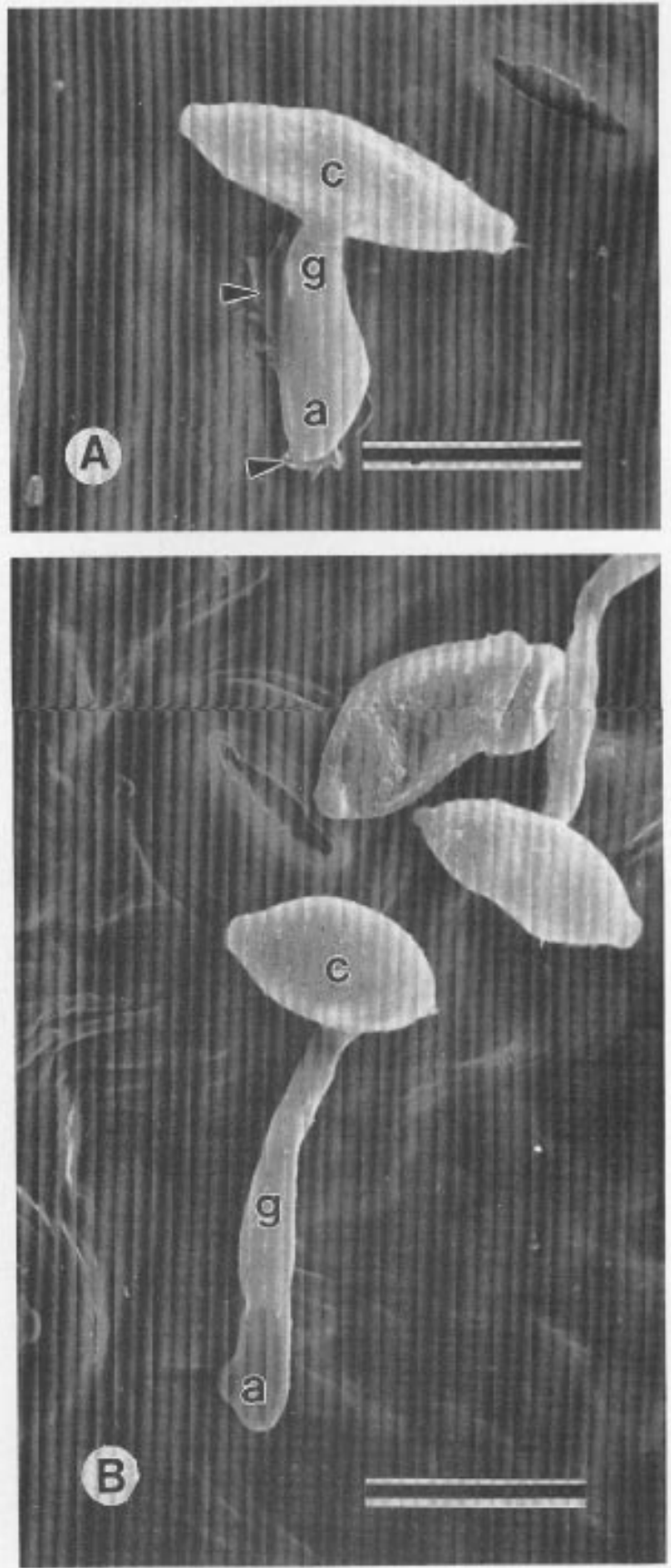

Fig. 7. Variable development of germ tubes and appressoria on immature leaves of the susceptible host plant, 'Wichita' pecan. Conidium with short germ tube and single lobed appressorium with points indicating apparent secretion along germ tube and around appressorium periphery (A). Conidium with long germ tube and double lobed appressorium (B) with two more conidia in upper portion of micrograph, one collapsed and the other with a long germ tube. Abbreviations: $\mathrm{c}=$ conidium, $\mathrm{g}=$ germ tube, $\mathrm{a}=$ appressorium. $\mathrm{Bars}=10 \mu \mathrm{m}(\mathbf{A}$ and $\mathbf{B})$.

$10 \mathrm{C}$ and D). Trichomes blanketed the 'Elliott' leaf and frequently abutted each other or were located within at least $20 \mu \mathrm{m}$ of each other. Trichomes were more sparse on 'Wichita' and often located up to 50 $\mu \mathrm{m}$ or more from each other. The major structural features on both tobacco and tomato leaves were awn-shaped trichomes. Tobacco leaf trichomes (Fig. 11A) apparently were glandular judging from the bulbous tip shape. Tomato trichomes had a pencil-shaped tip and did not appear to have a secretory function (Fig. 11B). Corn leaves did not have obvious trichomes (11C). 



Fig. 8. Variable development of germ tubes and appressoria on mature leaves of the susceptible host plant, 'Wichita' pecan. Conidium with no apparent germ tube and double lobed appressorium with point indicating apparent secretion around appressorium periphery (A). Conidium with long germ tube and single lobed appressorium with point indicating apparent secretion around appressorium periphery (B). Abbreviations: $\mathrm{c}=$ conidium, inactive $\mathrm{g}=$ germ tube, $\mathrm{a}=$ appressorium. Bars $=10 \mu \mathrm{m}(\mathbf{A}$ and $\mathbf{B})$.

\section{Discussion}

Rust fungi have been investigated more extensively than other fungi for nonhost reactions (Heath, 1974, 1987). Uredospores of Uromyces phaseoli var. vignae causing cowpea rust and conidia of Cladosporium caryigenum causing pecan scab have similar responses to host and nonhost leaves. Uredospores of cowpea rust germinated equally well on all hosts and nonhosts, with a couple of exceptions. Absence of germinated uredospores was attributed to lack of spore contact with leaf surface moisture due to abundant leaf hairs. $C$. caryigenum conidia germinated more frequently on resistant host leaves of 'Elliott' pecan than any other leaf and with equal frequency on the susceptible host, 'Wichita' pecan, and the nonhost, tobacco. About $50 \%$ fewer germ tubes were produced on tomato and corn than other genotypes. Micrographs demonstrated

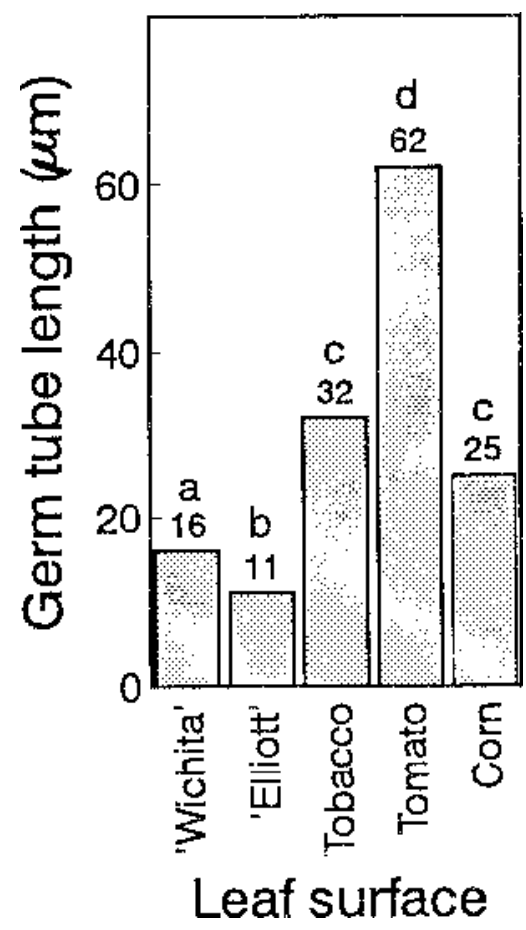

Fig. 9. Leaf genotype influence on germ tubes length. Data were subjected to logarithmic transformation before being treated by analysis of variance. Means with a common letter are not different, $P \leq 0.05$.

abundant trichomes on the tomato leaf surface, but none on corn. Awn-shaped trichomes could prevent spore contact on the tomato, but not corn. High germination frequency on resistant and nonhost genotypes, 'Elliott' pecan and tobacco, respectively, indicates germination inhibitors are not significant to scab resistance.

An appressorium must be formed over a stoma after the $U$. phaseoli uredospore forms a germ tube. Appressoria were formed by $60 \%$ of the germ tubes on resistant and susceptible host cowpea cultivars; whereas, much lower values were recorded on several nonhosts (Heath, 1974). We observed that $C$. caryigenum conidia often form germ tubes and the resulting appressorium in a direction away from, rather than toward, stomates. Latham and Rushing (1988) reported that $C$. caryigenum penetrates through the cuticle, not stomates. Appressoria were formed with equal frequency on both pecan cultivars and tobacco. Thus, high frequency of appressoria on genotypes not subject to disease development suggests appressorium, like germination, inhibitors may not be involved in scab resistance.

Uromyces phaseoli produced haustoria in $80 \%$ or more of the infection sites in host cultivars, but only rarely in nonhost plants. The first stage of $C$. caryigenum growth after cuticle penetration is subcuticular hyphae development (Rushing and Latham, 1991). We did not quantify development intermediate between appressoria and subcuticular hyphae which would be penetrating the leaf surface. However, formation of subcuticular hyphae was limited or absent in all plant genotypes except 'Wichita' pecan. Thus, subcuticular hyphae development was specific for the susceptible host leaf of 'Wichita' pecan.

Germ tube and appressorial development are not specific for either host, leaf surface, or pecan leaf age. Immature and mature leaves from 'Wichita', the susceptible host, and 'Elliott', a resistant host, promoted germ tube and appressorium development. Immature compared to mature leaves were more supportive of both growth stages on 'Elliott', but not 'Wichita'. Differences in 

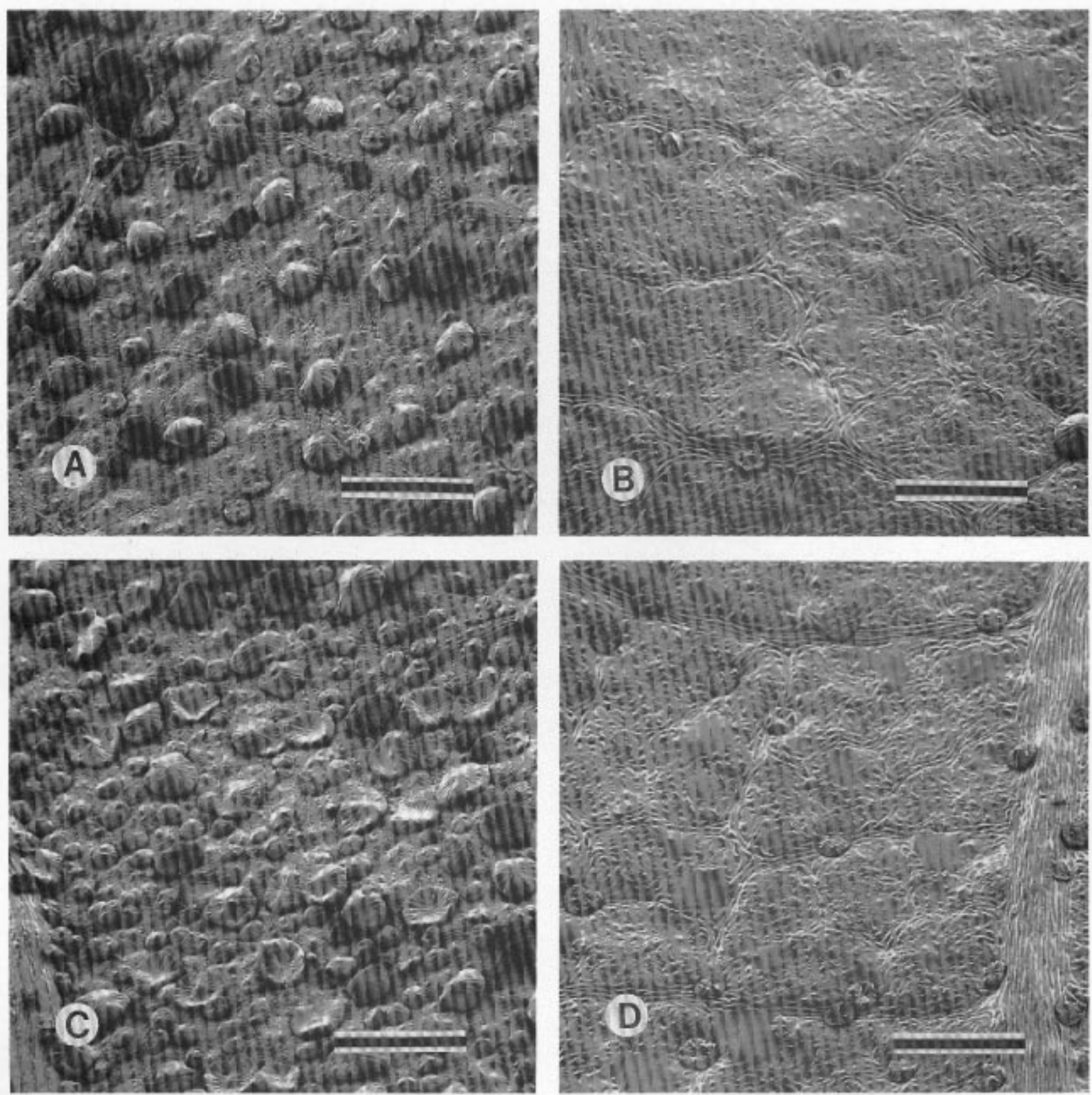

Fig. 10. Immature and mature leaf surface morphology of susceptible host 'Wichita pecan (A and $\mathbf{B}$, respectively) and resistant 'Elliott' pecan (C and $\mathbf{D}$, respectively). Bars $=200 \mu \mathrm{m}(\mathbf{A}$ to $\mathbf{D})$

the response of the two cultivars may be that immature and mature leaves were collected from different trees or could be related to trichome density. Micrographs demonstrated that trichomes were more dense on 'Elliott' than 'Wichita' leaves. Thus, a more humid environment may have been created on the 'Elliott' leaves used in the current study. Relative trichome frequency on 'Wichita' and 'Elliott' conflicts with an earlier report that trichomes were more dense on scab susceptible than scab resistant pecan cultivars (Wetzstein and Sparks, 1983). Reasons for the discrepancies in the two studies are not apparent, except that the earlier study used field grown plants and the current study used greenhouse grown plants.

The technology developed to conduct these studies would be adaptable to screening selections for scab susceptibility in a breeding program. A major objective in breeding pecans for humid climates is developing scab resistant genotypes (Sparks, 1992). Screening is a lengthy, laborious task involving field plots that must be maintained and monitored over hundreds of miles in the southeastern United States. Furthermore, warm, humid environmental conditions must occur within 28 days of budbreak for leaves to be susceptible to infection (Demaree, 1924; Gottwald, 1985) so that selections can be made. Humid conditions may be created naturally by climatic condition or artificially by overhead sprinklers. The first option is risky because environmental conditions are not conducive every year to scab development during leaf susceptibility. The second option is expensive considering the cost of constructing and operating overhead sprinklers. Furthermore, neither option ensures the warm temperatures essential for fungal spore germination (Gottwald, 1985).

Methodology developed for this study would provide many advantages over the current risky and expensive protocol of field testing. First, our technique provides carefully controlled environmental conditions so a testing program could proceed throughout the year. Seeds from controlled crosses could be germinated in any heated space available and leaves tested within weeks of germina- 

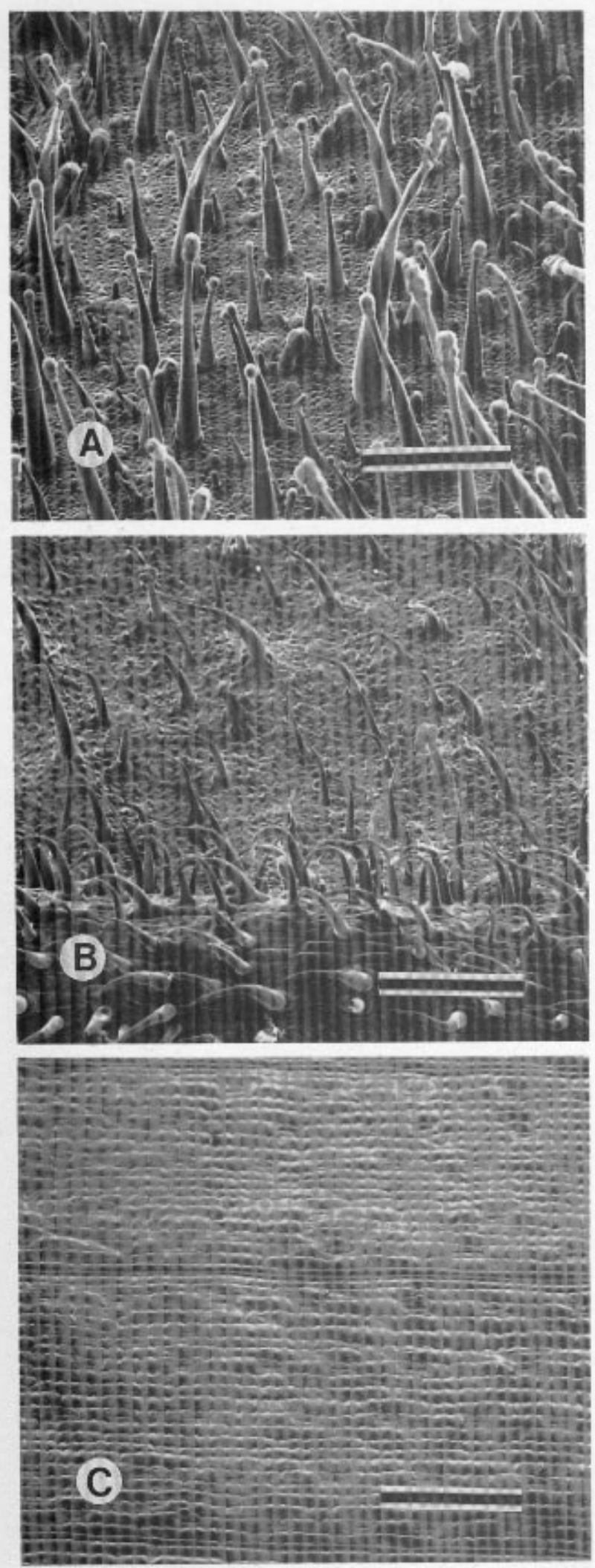

Fig. 11. Immature leaf surface morphology of nonhost plants tobacco (A), tomato (B), and corn (C). Bars $=200 \mu \mathrm{m}(\mathbf{A}-\mathbf{C})$.

tion. Second, testing can be confined to one geographic location, eliminating the need for personnel to travel to distantly located field plots. Third, the same plant selection can be tested with $C$. caryigenum isolated from throughout the pecan growing region to analyze the possibility of races within the species. Fourth, the reverse experiment could likewise be accomplished; that is, many different pecan genotypes could be tested with the same fungal isolate. Fifth, results would be available within a few days. Other advantages exist for using this technique in both breeding and research programs and only a portion have been highlighted.

In summary, methodology has been developed that merits evaluation for simplifying screening for scab resistance in pecan. Furthermore, specificity has been determined for germ tube, appressorium, and subcuticular hyphal development by $C$. caryigenum with respect to plant genotype, leaf surface, and pecan leaf maturity. C. caryigenum conidia produced germ tubes and appressoria even on leaves of a monocotyledon, both adaxial and abaxial leaf surfaces, and on both mature and immature resistant and susceptible pecan leaves. Germ tube and appressoria frequency varied among genotypes and with leaf maturity, but was not correlated with host plant resistance. For example, the resistant host cultivar 'Elliott' supported a significantly higher frequency of germ tube formation than the susceptible host plant, 'Wichita'. Subcuticular hyphae development was the fungal stage that occurred only in a susceptible host. Thus, mechanism(s) for halting C. caryigenum growth inherent to resistant pecan genotypes appears to operate at a stage later than either germ tube or appressorium development on the cuticle surface.

\section{Literature Cited}

Cason, K.M.T. and I.E. Yates. 1991. Anatomical characterization of pecan shoots with tissue- and cultivar-specific resistance to scab. Phytopathology $81: 1162$.

Callow, J.A., M.T. Estrada-Garcia, and J.R. Green. 1987. Recognition of nonself: the causation and avoidance of disease. Ann. Bot. 60:3-14.

Chortyk, O.T., I.E. Yates, and C.C. Reilly. 1995. Changes in cuticular compounds of developing pecan leaves. J. Amer. Soc. Hort. Sci. 120:329_ 335.

Demaree, J.B. 1924. Pecan scab with special reference to sources of the early spring infections. J. Agr. Res. 28:321-329.

Gomez, K.A. and A.A. Gomez. 1984. Statistical procedures for agricultural research. Wiley, New York.

Gottwald, T.R. 1985. Influence of temperature, leaf wetness period, leaf age, and spore concentration on infection of pecan leaves by conidia of Cladosporium caryigenum. Phytopathology 75:190-194.

Gueldner, R.C., I.E. Yates, C.C. Reilly, B.W. Wood, and M.T. Smith. 1994. Levels of a hydrojuglone glucoside in developing pecan leaves in relation to scab susceptibility. J. Amer. Soc. Hort. Sci. 119:498-504.

Heath, M.C. 1974. Light and electron microscope studies of the interactions of host and nonhost plants with cowpea rust-Uromyces phaseoli var. vignae. Physiol. Plant Pathol. 4:403-414.

Heath, M.C. 1987. Host vs. nonhost resistance, p. 25-34. In: UCLA Symp. Mol. Cell Biol. Molecular strategies for crop protection. Alan R. Liss, New York.

Hedin, P.A., V.E. Langhans, and C.H. Graves, Jr. 1979. Identification of juglone in pecan as a possible factor of resistance to Fusicladium effusum. J. Agr. Food Chem. 27:92-94.

Latham, A.J. and A.E. Rushing. 1988. Development of Cladosporium caryigenum in pecan leaves. Phytopathology 78:1104-1108.

McBryde, M.C. 1936. A method of demonstrating rust hyphae and haustoria in unsectioned leaf tissue. Amer. J. Bot. 23:686-689.

Rushing, A.E. and A.J. Latham. 1991. Some ultrastructural observations of Cladosporium caryigenum growth in pecan leaves. Phytopathology 81:11021108.

Sparks, D. 1992. Pecan cultivars: The orchard's foundation. Pecan Production Innovations, Watkinsville, Ga.

Wetzstein, H.Y. and D. Sparks. 1983. Anatomical indices of cultivar and agerelated scab resistance and susceptibility in pecan leaves. J. Amer. Soc. Hort. Sci. 108:210-218.

Wood, B.A., T.R. Gottwald, and C.C. Reilly. 1988. Pecan phylloplane chemicals influence germination of pecan scab conidia. J. Amer. Soc. Hort. Sci. 113:616-619. 